\title{
Feasibility of using straw in a strong, thin, pulp moulded packaging material
}

Curling, Simon; Laflin, Nicholas; Davies, Gwenda; Ormondroyd, Graham; Elias, Robert

\section{Industrial Crops and Products}

Published: 01/03/2017

Peer reviewed version

Cyswllt i'r cyhoeddiad / Link to publication

Dyfyniad o'r fersiwn a gyhoeddwyd / Citation for published version (APA):

Curling, S., Laflin, N., Davies, G., Ormondroyd, G., \& Elias, R. (2017). Feasibility of using straw in a strong, thin, pulp moulded packaging material. Industrial Crops and Products, 97, 395-400.

\footnotetext{
Hawliau Cyffredinol / General rights

Copyright and moral rights for the publications made accessible in the public portal are retained by the authors and/or other copyright owners and it is a condition of accessing publications that users recognise and abide by the legal requirements associated with these rights.

- Users may download and print one copy of any publication from the public portal for the purpose of private study or research.

- You may not further distribute the material or use it for any profit-making activity or commercial gain

- You may freely distribute the URL identifying the publication in the public portal?
}

Take down policy

If you believe that this document breaches copyright please contact us providing details, and we will remove access to the work immediately and investigate your claim. 
1

\title{
Feasibility of using straw in a strong, thin, pulp moulded packaging
}

\section{material.}

(1)

S.F Curling ${ }^{1 *}$, N Laflin ${ }^{1}$, G.M Davies ${ }^{1}$, G.A Ormondroyd ${ }^{1,2}$, R.M Elias ${ }^{1}$.

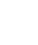

${ }^{1}$ BioComposites Centre, Bangor University, Bangor, Gwynedd LL57 2UW United Kingdom

${ }^{2}$ Department of Architecture and Civil Engineering, University of Bath, Claverton Down, Bath, BA2 7AY, UK

s.curling@bangor.ac.uk (corresponding author)

n.j.laflin@ bangor.ac.uk

g.m.davies@bangor.ac.uk

g.ormondroyd@bangor.ac.uk

r.m.elias@bangor.ac.uk

\begin{abstract}
Packaging is a ubiquitous commodity that is being used in increasing quantities. This increased use has led to a problem with disposal, with increased quantities of used packaging being sent to landfill. One sustainable solution suggested is the use of biobased, biodegradable packaging. An example of this is paper based pulp moulded products which have been used previously for a number of packaging applications. In this paper the feasibility of replacing paper fibre with waste cereal straw fibre is examined. The aim was to produce materials that could be used to form flat, round trays, such as
\end{abstract}


those used in supporting shrink wrapped food items. The material was required to have properties that matched existing alternatives, such as expanded polystyrene, in terms of physical and mechanical characteristics but with an enhanced level of biodegradability. The data showed that the pulp moulded material containing up to $80 \%$ straw performed significantly better compared to expanded polystyrene in tensile properties (modulus of $0.47 \mathrm{MPa}$ for an $80 \%$ straw mix compared to $0.16 \mathrm{MPa}$ for EPS). Modulus under bending was shown to be lower for straw based materials compared to EPS (0.015 MPa compare to $0.035 \mathrm{MPa}$ ). Adjustments in product thickness allowed performance parameters to be met. Wet end addition of chemicals was successfully used to provide water resistance without affecting other variables. In addition to exhibiting good performance characteristics the pulp moulded material was shown to be biodegradable, exhibiting $20 \%$ mass loss after only 4 weeks covered in unsterile soil.

Highlights

- Pulp moulded flat, round packaging trays were produced using straw.

- Intrinsic tensile properties improved compared to Expanded Polystyrene (EPS)

- Intrinsic flexural properties of straw material were lower than EPS.

- Product performance matched EPS performance with changes to product thickness

- Straw based materials were biodegradable.

Key words: Pulp moulding, straw, packaging, renewable, biodegradable

\subsection{Introduction}


Single use packaging materials are a ubiquitous feature of modern society and, in the United Kingdom, have shown rapid increase in their use. However, with recent legislative pressures, such as those described in the European Union Landfill directive, [European Union 1999] and other societal consumer concerns [Hall et al 2010], alternative biobased solutions to petrochemical based plastic packaging are being sought. In terms of managing waste at the end of life of the product, enhanced biodegradability of biobased packaging is an essential asset [Siracusa et al 2008, Song et al 2009] as many packaging materials are not reused but thrown into waste - with these non biodegradable products adding to the land fill burden. A key attribute of a biobased packaging product should, therefore, be an improvement in biodegradability over existing alternatives. However, biodegradable items can cause contamination in plastic recycling and ideally therefore, the whole product should be biodegradable at the level of either a community or household composting regime [Davis and Song (2006)]. One currently used form of biobased packaging moulded paper pulp packaging [Guray et al 2003; Zabaniotou and Kassidi 2015], where the packaging is mainly used for its cushioning properties [Eagleton and Marcondes 1994; Hoffmann, 2000]. Other studies [Gurav et al 2003,] have investigated the strength properties of biobased moulded packaging created via wet forming. Wet forming uses a water borne pulp fibre suspension shaped in a mould with simultaneous or subsequent (based on the equipment used) dewatering and drying. Wet formed packaging material of this type has mainly used recycled paper and cardboard fibre, although in some cases, such as food contact, this is not deemed viable due to contamination from inks etc. in the pulp. An alternative to waste paper would be pure Kraft pulp but this may not be economically viable. However, other non-wood based lignocellulose feedstocks, such as cereal straw, could be used to produce the pulp. Each year approximately $1.45 \mathrm{Mt}$ of cereal straw [Glithero 2013] are reincorporated into arable soil. This is partly as a waste management issue although the straw does also serve as a soil amendment and improver. On availability grounds, 
straw can therefore be considered a good candidate as a raw material in biobased materials. In terms of packaging, straw based packaging applications have been developed [Vargas et al 2012] although, to the author's knowledge, the particular use of straw in the manufacture of thin sheet materials, does not appear to have been reported. These thin sheet materials, commonly made from expanded polystyrene are frequently used to help support products in food applications, such as the round trays used in packaging to support cakes, pastries or pizzas to stop bending of items during shrink wrapping and display. The current study is part of a larger project to develop a flat, round straw based tray that could be used for the applications noted above.

In terms of moving a biobased product to commercial viability the product must perform mechanically at least as well as an established alternative but also be biodegradable. This paper therefore investigates the feasibility of using straw pulp to produce material suitable to form a pulp moulded, flat, round tray by testing the materials' and products' mechanical and biodegradation properties. Expanded polystyrene products are used as a comparative benchmark for required properties.

\subsection{Materials and methods}

\subsection{Preparation and Characterisation of raw materials.}

Wheat straw (Triticum aestivum cv Solstice) was selected as the straw component. The straw was cut into pieces smaller than $5 \mathrm{~cm}$ and then refined using a $30 \mathrm{~cm}$ pressurised refiner (Andritz Sprout Bauer). Briefly, this refining process consisted of the followingn steps;

The straw was fed via a cooker screw into a 60 litre digester, with a nominal residence time of 60 seconds in the cooker screw and digester. Steam pressure in the cooker/digester was maintained at $0.94 \mathrm{MPa}$ using steam at $390^{\circ} \mathrm{C}$. On leaving the cooker/digester, the straw was fed, via a second screw feed, into the refiner, and passed between two $30 \mathrm{~cm}$ diameter refiner 
plates, with a parallel bar configuration, to form the fibre (fuller details can be found in Ormondroyd et al 2016).

The starting straw and resultant pulp pre-mix were chemically characterised as follows:

2.1.1 Wax/Extractives: Replicate samples were extracted with toluene, acetone, and methanol (4:1:1) for 8 hrs using soxhlet extraction (at least 50 solvent cycles). Wax/extractive content were calculated and expressed as percentage on a dry weight basis.

2.1.2 Klason Lignin: Tappi standard method 222 [Tappi 2006] was used to determine lignin concentration in the samples. This method used acid hydrolysis of the polysaccharides in $72 \%$ sulphuric acid leaving the lignin in solid form. Lignin content was expressed as percentage on dry weight basis.

2.1.3 Alpha cellulose and Hemicellulose: The alpha cellulose and hemicellulose contents of the samples were determined by analysis of holocellulose isolated using the sodium chlorite method [Browning 1967] This used acidified sodium chlorite to delignify the samples leaving holocellulose, which was extracted using $17 \%$ sodium hydroxide. Following neutralisation with acetic acid and washing with water and methylated spirit, the alpha cellulose was separated by filtration. Composition was determined gravimetrically as a percentage of original dry weight. Hemicellulose content was determined by neutralisation of the filtrate and precipitation of hemicellulose via addition of copious ethanol. Following drying of the hemicelluloses the composition was determined gravimetrically as a percentage based on original dry weight of sample. 
2.1.4 Ash: Oven-dried material was ashed in a muffle furnace at $525^{\circ} \mathrm{C}$ for $16 \mathrm{hrs}$, with the ash content calculated as a percentage on dry weight basis.

2.2 Pulp moulding. The pulp for the moulding of the material was prepared in a mixing tank of a proprietary pulp moulder (Valueform, UK) utilising a plain transfer moulding process. Kraft paper pulp fibre was obtained from commercial dried sheets which were pulped in water before adding to the straw fibre pulp at three differing ratios - a base $100 \%$ straw mix, a 80/20 straw/Kraft mix and a 60/40 straw/Kraft mix. To these mixes an anti-foaming agent (Percol, BASF) and a water repellent additive (Basoplast, BASF) were added. The water repellent additive was included to decrease the water absorbance of the final product, although some samples without added water repellent were produced to test the efficacy of the additive. The anti-foaming agent was added to stop a foam or froth forming in the pulp as this was found to cause holes in the product during the moulding cycle. Although the exact details of the moulding cycle are not reported for potential commercial reasons, the procedure consisted of immersion of the mould into the pulp, filling of the mould, vacuum removal of water and pressing of the pulp using proprietary cycling schedules. The moulded material was dried by hot air convection in an oven at $100^{\circ} \mathrm{C}$ for 30 minutes.

\subsection{Characterisation of pulp}

The $\mathrm{pH}$, drainage and particle size distribution of the pulp were measured prior to moulding. The drainage of the pulp was assessed using Canadian Standard Freeness of the pulp following the method described in ISO 5267-2 [ISO 2001]. Particle size distribution was determined by drying the pulp to a fibrous state, with no agglomerations, and then sieving through a sequential series of wire mesh sieves with frequency allocation based on mass fraction. 
In the investigation detailed in this paper the $100 \%$ straw mix did not produce a moulded product that was suitable for use or analysis. Therefore, only samples representing the 80/20 and 60/40 mix were analysed in terms of physical characteristics, mechanical properties (tensile and flexural properties, water absorbency and biodegradation. Due to limitations placed by the dimensions of the product, in this case a round tray, non-standard testing procedures were used in some instances. To validate the study, controls of similar existing products were tested in the same way as the moulded products.

\subsubsection{Physical characterisation}

The thickness of the product material was determined using digital callipers and reported as a mean value of at least 5 replicates per sample. The density of the material was determined gravimetrically.

\subsubsection{Mechanical testing}

The tensile properties of the product materials (conditioned at $20^{\circ} \mathrm{C}$ and $65 \%$ relative humidity $(\mathrm{RH})$ ) were determined using an Instron testing machine (Instron, High Wycombe, UK) using a $5 \mathrm{kN}$ load cell, in a controlled environment $\left(20^{\circ} \mathrm{C}\right.$ and $\left.65 \% \mathrm{RH}\right)$. Samples of size $80 \mathrm{~mm}$ by $25 \mathrm{~mm}$ by thickness (See Table 2 for thickness) with a gauge length of $50 \mathrm{~mm}$ were subjected to a uniform rate of tensile force until failure. Samples of EPS of the same dimensions were also tested in the same way. Modulus (equation 1) was determined from the linear portion of the load/deformation relationships. 
173 Where $\mathrm{F}=$ force applied $(\mathrm{N}), \mathrm{w}=$ width $(\mathrm{mm}), \mathrm{d}=\operatorname{depth}(\mathrm{mm}), \Delta=\operatorname{deflection}, \mathrm{l}=$ span length

175 The flexural properties of the product material were tested under 3 point loading also using an 176 Instron testing machine (Instron) using a $5 \mathrm{kN}$ load cell, in a controlled environment $\left(20^{\circ} \mathrm{C}\right.$ and $17765 \% \mathrm{RH})$. Specimen size was $80 \mathrm{~mm}$ by $25 \mathrm{~mm}$ by thickness and the test span length of $50 \mathrm{~mm}$. 178 Bending was performed to a set deflection rather than rupture as it was observed that the straw based material did not give an identifiable rupture point during testing. Initial tests were performed to identify the linear portion of the deflection curve prior to the yield point to set this deflection point. Following a small preload a uniform rate of loading was applied until a maximum deflection of $5 \mathrm{~mm}$ was obtained. The modulus (equation 2) was determined from the resulting linear portion of the deflection graph. Samples of EPS of the same dimensions were also tested in the same way to allow comparative analysis.

186 Modulus (bending) $=\frac{F l^{3}}{4 \Delta b d^{3}}$

Where $\mathrm{F}=$ force applied $(\mathrm{N}), \mathrm{L}=$ span length, $\Delta=$ deflection, $\mathrm{b}=$ breadth, $\mathrm{d}=$ depth.

\subsubsection{Water absorbance}

Water absorbance of the product material was determined using the Cobb test [Jacobs et al 2002]. A known volume of water $(100 \mathrm{ml})$ was applied to a defined area of the material $\left(100 \mathrm{~cm}^{2}\right)$ and uptake of water was determined gravimetrically after a period of 120 seconds. The water absorbance of samples not treated with the water repellent was also measured to determine the efficacy of the additive. 
197 The biodegradability of the samples was determined using a soil box method utilising unsterile soil (Li et al 2007, M. Venäläinen et al 2014), Samples (11 cm x 3cm x thickness) were cut from the test products. The samples were placed into a soil box where the samples rested on and were covered by unsterile moist (30-35\% moisture content) soil (John Innes No 2). The test assemblages were maintained at room temperature for four weeks before assessment by visual and mass loss criteria. This test is a non-standard test developed from methods described by Curling et al (2002) and the standard method ENV807 (British standards 2001).

204

\subsection{Statistical procedures}

Where appropriate simple statistical analysis of the data was performed using t-tests assuming equal variances following ANOVA testing.

\subsection{Results and Discussion}

\subsection{Raw material Characterisation}

211 The straw material was analysed for chemical content pre and post refining treatment. The

212 data shown in Figure 1 indicates that the refining changed the composition of the fibre relative to the straw by removing some of the hemicellulose (likely water soluble fractions [Tappi 2015] and ash.

Figure 1 Chemical composition of straw pre and post refining labelled straw and fibre respectively (Error bars show standard deviation). 
221 The pulp of the 80/20 and 60/40 mixes were analysed on the basis of $\mathrm{pH}$ and Canadian standard

222 freeness and compared to the base refined straw (Table 1). The data shows that addition of the

223 Kraft pulp reduced the Canadian Standard Freeness (CSF) (all differences significant at

$224 \mathrm{p}=0.05$ ) and increased the $\mathrm{pH}$. The CSF is an important measure when pulp moulding as it

225 indicates the ease at which the moulded product is dewatered - with faster dewatering leading

226 to better integrity and improved drying. Improved drying may be an important factor when considering economic costs of drying the product material.

The determination of the particle size of the mixes in comparison to the base refined straw shows (Figure 2) that the base straw has a majority of shorter size fibres $(200-400 \mu \mathrm{m})$ with a general but declining distribution of larger size particles, whilst the 60/40 mix has a skewed distribution towards larger fibres $(1680 \mu \mathrm{m}$ and above). The $80 / 20 \mathrm{mix}$ in contrast shows a distribution of two distinct sizes at $200-400 \mu \mathrm{m}$ and $1680 \mu \mathrm{m}$ and above. The large particle size was assigned to the Kraft paper fraction with the smaller size assigned to the straw.

Figure 2. Particle size distribution of pulp mixes.

\subsection{Characterisation of moulded material}

240 As stated moulded products produced using 100\% straw in this investigation did not produce material suitable for testing or use. It was found during moulding that the product had no wet strength and could not be removed from the mould without breaking. It was assumed that this was due to the lack of the longer Kraft pulp fibres binding the material together. Therefore, the physical characteristics of the moulded material produced from the $80 / 20$ and $60 / 40$ mixes only, is reported. The physical characteristics (Density and thickness) of the moulded material 
compared to a commercial expanded polystyrene packaging sheet are shown in table 2 . The

247 data shows that the straw based moulded materials had a higher level of variation in thickness (based on standard deviation of thickness). This may have been due to springback of the straw fibres after moulding. However, the $60 / 40$ mix was statistically significantly thinner (at $p=0.05$ ) than the EPS whilst the $80 / 20$ mix was statistically significantly thicker (at $\mathrm{p}=0.05$ ). The data also shows that increasing the level of Kraft pulp increased the density of the material (statistically significant at $\mathrm{p}=0.05$ ), although it is clear that the straw based materials have a much higher density than the EPS. As the moulded materials had a similar thickness to the EPS but much higher density the weight per unit area of the moulded materials will much higher than the EPS. This may have implications on economics where larger weight transported resultants in a higher cost, although economic metrics were not part of the study detailed in this paper.

\subsubsection{Mechanical testing}

These tests used nonstandard test sizes making comparison with other studies and materials difficult. Therefore the mechanical properties data has been assessed using two approaches; a) the intrinsic mechanical properties of the material and $b$ ), the performance of the moulded product in comparison to the commercial (i.e. EPS) product

The values of the tensile properties of the materials were determined from the linear portion of the load/deformation relationship (representative examples shown in figure 3).

Figure 3. Representative examples of the load/deformation curves for the pulp moulded and EPS samples 
271 The data shows (table 3) that addition of the Kraft pulp significantly increases the tensile 272 modulus, (significant at $\mathrm{p}=0.05$ ) of the $60 / 40 \mathrm{mix}$ compared to the $80 / 20 \mathrm{mix}$. This may be due 273 to the presence of the larger particles identified by the particle size distribution (Figure 2). In 274 comparison to the EPS both pulp mixes gave modulus values that were significantly higher (at $275 \mathrm{p}=0.05)$ than EPS.

277 In terms of the flexural properties of the materials, values for modulus under bending (stiffness) were determined, based on the force required to bend the material by $5 \mathrm{~mm}$. This was within the linear elastic defamation region and takes the effect of material thickness into account. The data (Table 3) shows that the moulded material gave statistically lower values for this modulus compared to the EPS, indicating that on a unit by unit comparison the pulp moulded material had a lower stiffness the EPS.

In terms of the performance of the products the maximum loads in both the tensile and flexural directions were compared, (Table 4). The data shows that the mean maximum load achieved by the $60 / 40$ mix was significantly higher than that of the EPS and the $80 / 20$ mix. The mean maximum loads for the $80 / 20 \mathrm{mix}$ and the EPS were not statistically different. This data is based on products with different thicknesses, but it does indicate that the pulp moulded product as produced can match the tensile performance of the EPS, with an adjustment in thickness. The maximum flexural load required to reach $5 \mathrm{~mm}$ deflection for the $60 / 40$ mix product was statistically significantly (at $\mathrm{p}=0.05$ ) lower than both the $80 / 20$ mix product and the EPS product. However, the 80/20 mix product with its increased thickness sustained a maximum flexural load that was not significantly different to that of the EPS product. 
The combined data from the tensile and flexural tests indicates that products moulded from the straw/paper material in the correct composition can match the performance of the EPS products, although changes in thickness may be required.

\subsubsection{Water absorbance}

Water absorbancy can be a key atribute in packaging as strength and cohesion of materials can be impaired by too much water. Also, if the material were to be used in food packaging water sorption from the food product would need to be limited. Therefore, the wwater absorbance of the materials was assessed by determining the Cobb value of the materials. A low value shows low absorbance of water, with business paper having a Cobb value of 22-26, unsized paper generally having a Cobb value of 50+ and corrugated cardboard having a Cobb value of 120 140 [Jacobs et al 2002]). The data (Figure 4) shows that the EPS had a significantly lower level of water absorption than the moulded products. The moulding process did include the addition of a water repellent, as without it, the water absorbency would be significantly higher. Samples without the additive gave Cobb values of $2664.78 \pm 484.2$ for the $60 / 40 \mathrm{mix}$ and $3058.2 \pm 113.5$ for the $80 / 20$ mix: data that show the effectiveness of the additive. Even though the EPS showed significantly lower water absorbance the values obtained for the moulded materials are on the lower end of the scale for equivalent materials.

Figure 4. Water absorbance of pulp moulded material compared to EPS

\subsubsection{Biodegradability}

Following the four weeks exposure in the soil test there were clear differences in appearance between the EPS and moulded material, with the moulded material showing clear signs of microbiological growth and biodegradation. On removing the samples from the soil all of the 
moulded material samples broke into two or more pieces whilst the EPS remained completely intact (Figure 5).

Figure 5. Comparison of pre soil exposure (A) and post soil exposure (B) of EPS (left) and straw based material (right)

Mass loss of the samples during the four week exposure was determined and the data (Table 5) shows a significant (at $\mathrm{p}=0.05$ ) difference between the straw based material and the EPS. The data shows that over $20 \%$ of the $80 \%$ straw based material was degraded after only four weeks soil exposure, implying that the straw based material would be readily compostable. The EPS samples exhibited a slight average weight gain which is attributed to unobserved adhering soil.

\subsection{Conclusions}

The study demonstrated the successful production of material suitable for thin flat pulp moulded materials containing up to $80 \%$ straw. Chemical additives were shown to be effective when added at the "wet end" of the moulding process, for example to provide the required water resistance. In terms of intrinsic material properties the moulded material had a tensile modulus higher than the EPS but a lower modulus in bending. In assessing the performance of the products the noted deficiencies in bending strength could be alleviated by using thicker materials. In terms of physical characteristics, the pulp moulded material was heavier than EPS, which may have economic implications. Importantly, it was also shown that the straw based material was biodegradable at ambient temperature in soil, which is a great contrast to the non biodegradability of EPS. 
In summary the data presented shows for the first time that it is feasible to produce a flat, thin pulp moulded product derived predominately from cereal straw that possessed the required physical and mechanical performance but that was also biodegradable.

\subsection{Acknowledgements}

This research was carried with funding from the UK Technology Strategy Board under DTI Project No: TP AB346C. The authors would like to acknowledge the help of Valueform UK.

The authors would also like to acknowledge the considerable technical advice from Mr David Roberts in the running of the pulp moulding machine.

\subsection{References}

British Standards Institute (2001) DD ENV 807:2001Wood preservatives. Determination of the effectiveness against soft rotting micro-fungi and other soil inhabiting micro-organisms. British Standards Institute, London, United Kingdom, 44pages

Browning B.L. (1967) Methods of Wood Chemistry volume 1 Interscience New York USA 361

Davis G., Song J.H. (2006). Biodegradable packaging based on raw materials from crops and their impact on waste management. Ind. Crops Prod. 23 147-161 
Eagleton D G and. Marcondes J A (1994) Cushioning properties of moulded pulp. Packag.

European Union (1999) Landfill Directive: Council Directive 1999/31/EC

373 Glithero N J, Wilson P, Ramsden J. (2013) Straw use and availability for second generation

Biofuels in England. Biomass and BioEnergy 55311 - 321

375

Gurav S.P, Bereznitski A, Heidweiller A, Kandachar P.V. (2003) Mechanical properties of

paper-pulp packaging. Composites Sci. Technol. 63 1325-1334

378

Hall C.R, Campbell B.L, Behe B.K, Yue C, Lopez R.G, Dennis J,H. (2010). The Appeal of 380 Biodegradable Packaging to Floral Consumers. Hortscience 45 (4):583-591.

Hoffmann, J. (2000) Compression and cushioning characteristics of moulded pulp packaging

Packag. Technol. Sci., 13, (5), 211-220 DOI: 10.1002/1099-1522(200009)13:5<211::AID-

PTS515>3.0.CO;2-0

385

ISO (2001) ISO Method 5267-2:2001(en) Pulps Determination of drainability— Part 2:

"Canadian Standard" freeness method 

spectroscopy. Carbohydr. Res., 337, 711-717.

392

Li G, Nicholas D.D, Schultz T.P. (2007) Development of an accelerated soil-contact decay test. Holzforschung, 61, 214-218

395

396

Ormondroyd GA, Källbom SK, Curling SF, Stefanowski BK, Segerholm BK, (2016). Water 397 sorption, surface structure and surface energy characteristics of wood composite fibres refined at different pressures. Wood Mater. Sci. Eng., 1-8 DOI: $10.1080 / 17480272.2016 .1150343$

400

401

Siracusaa V, Rocculib P, Romanib S Dalla Rosa M (2008). Biodegradable polymers for food 402 packaging: a review. Trends in Food Sci. Technol. 19, 634-643

403

404

Song J. H, Murphy R. J, Narayan R and Davies G. B. H (2009). Biodegradable and

405 compostable alternatives to conventional plastics. Philos. Trans. Royal Soc. B. 364, $2127-$ 2139. doi:10.1098/rstb.2008.0289

407

408

Tappi (2006) Acid-insoluble lignin in wood and pulp. Test Method TAPPI_ANSI T 222 om409 02

410

411 Tappi (2015) Water absorptiveness of sized (non-bibulous) paper paperboard and corrugated fiberboard (Cobb test) Test Method TAPPI_ANSI T 441 om-13. 
414 Vargas F, Gonzalez Z, Sanchez R, Jimenez L, Rodrguez, A. (2012) Cellulosic Pulps of cereal 415 straws as raw material for the manufacture of ecological packaging. BioResources 7 (3) 4161$416 \quad 4170$

417 Venäläinen M., Partanen H., Harju A. (2014). The strength loss of Scots pine timber in an

418 accelerated soil contact test. Int. Biodeterior. Biodegrad. 86 150-152

419

420 Zabaniotou A, Kassidi E (2015) Life cycle assessment applied to egg packaging made from

421 polystyrene and recycled paper. J. Clean. Prod. 11, (5), 549-559

422

423 
425 Table 1. Characterisation of pulp mixes.

\begin{tabular}{ccc}
\hline Pulp mix & $\begin{array}{c}\text { Canadian Standard Freeness } \\
(\mathrm{ml})\end{array}$ & $\mathrm{pH}$ \\
\hline Base straw & $740.6 \pm 7.76$ & 5 \\
$80 / 20$ & $725.3 \pm 2.8$ & 5.5 \\
$60 / 40$ & $230.0 \pm 14.5$ & 8.6 \\
\hline
\end{tabular}

426

427

428

429

\begin{tabular}{ccc}
\hline Sample & $\begin{array}{c}\text { Thickness } \\
\mathrm{mm}\end{array}$ & $\begin{array}{c}\text { Density } \\
\mathrm{kg} / \mathrm{m}^{3}\end{array}$ \\
\hline $60 / 40$ & $2.67 \pm 0.3$ & $147.15 \pm 3.4$ \\
$80 / 20$ & $4.54 \pm 0.28$ & $120.20 \pm 5.5$ \\
EPS & $3.95 \pm 0.1$ & $33.20 \pm 0.9$
\end{tabular}

430

431

432

Table 3 Intrinsic mechanical properties of materials

\begin{tabular}{lcc}
\hline Sample & $\begin{array}{c}\text { Modulus in tensile } \\
(\mathrm{MPa})\end{array}$ & $\begin{array}{c}\text { MOE under bending } \\
(\mathrm{MPa})\end{array}$ \\
\hline $60 / 40$ & $0.68 \pm 0.04$ & $0.028 \pm 0.006$ \\
$80 / 20$ & $0.47 \pm 0.14$ & $0.015 \pm 0.005$ \\
EPS & $0.16 \pm 0.009$ & $0.035 \pm 0.007$ \\
\hline
\end{tabular}


436 Table 4. Comparative performance of products

\begin{tabular}{lcc}
\hline Sample & $\begin{array}{c}\text { Max Tensile load } \\
(\mathrm{N})\end{array}$ & Max Flexural load \\
& $81.99(11.44)$ & $4.61 \pm 0.18$ \\
\hline $60 / 40$ & $65.00(6.48)$ & $2.02 \pm 0.25$ \\
$80 / 20$ & $67.20(2.64)$ & $4.02 \pm 0.47$ \\
EPS & & \\
\hline
\end{tabular}

437

438

439

440 Table 5. Mass loss of samples after four weeks exposure to unsterile soil

\begin{tabular}{cc}
\hline Sample & $\begin{array}{c}\text { Mean Mass loss } \\
(\% \text { based on original dry mass })\end{array}$ \\
\hline EPS & $-1.9 \pm 1.97$ \\
$60 / 40$ & $12.78 \pm 3.76$ \\
$80 / 20$ & $21.4 \pm 3.98$ \\
\hline
\end{tabular}

441

442 
Figure Captions

444

445 Figure 1 Chemical composition of straw pre and post refining labelled straw and fibre

446 respectively (Error bars show standard deviation).

447

448 Figure 2. Particle size distribution of pulp mixes

449

450 Figure 3. Representative examples of the load/deformation curves for the pulp moulded and 451 EPS samples

452

453 Figure 4. Water absorbance of pulp moulded material compared to EPS

454

455 Figure 5. Comparison of pre soil exposure (A) and post soil exposure (B) of EPS (left) and 456 straw based material (right)

457 